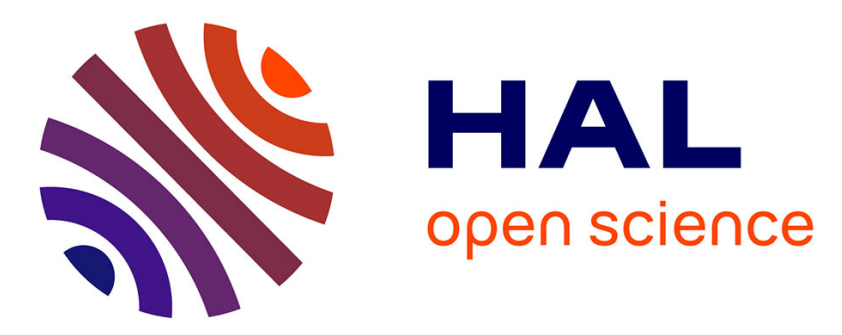

\title{
Energetics of competing chiral supramolecular polymers
}

Virgile Ayzac, Mohammed Dirany, Matthieu Raynal, Benjamin Isare, Laurent

Bouteiller

\section{To cite this version:}

Virgile Ayzac, Mohammed Dirany, Matthieu Raynal, Benjamin Isare, Laurent Bouteiller. Energetics of competing chiral supramolecular polymers. Chemistry - A European Journal, 2021, 10.1002/chem.202100645 . hal-03209211

\section{HAL Id: hal-03209211 \\ https://hal.sorbonne-universite.fr/hal-03209211}

Submitted on 27 Apr 2021

HAL is a multi-disciplinary open access archive for the deposit and dissemination of scientific research documents, whether they are published or not. The documents may come from teaching and research institutions in France or abroad, or from public or private research centers.
L'archive ouverte pluridisciplinaire HAL, est destinée au dépôt et à la diffusion de documents scientifiques de niveau recherche, publiés ou non, émanant des établissements d'enseignement et de recherche français ou étrangers, des laboratoires publics ou privés. 


\title{
Energetics of Competing Chiral Supramolecular Polymers
}

\author{
Virgile Ayzac, ${ }^{[a]}$ Mohammed Dirany,${ }^{[a]}$ Matthieu Raynal, ${ }^{[a]}$ Benjamin Isare, ${ }^{[a]}$ and Laurent Bouteiller ${ }^{[\mathrm{a}]}$
}

\begin{abstract}
Chirality can have unexpected consequences including on properties other than spectroscopic. We show herein that a racemic mixture of bis-urea stereoisomers forms thermodynamically stable supramolecular polymers that result in a more viscous solution than for the pure stereoisomer. The origin of this macroscopic property was probed by characterizing the structure and stability of the assemblies. Both racemic and non-racemic bis-urea stereoisomers form two competing helical supramolecular polymers in solution: a double and a single helical structure at low and high temperature, respectively. The transition temperature between these assemblies, as probed by spectroscopic and calorimetric analyses, is strongly influenced by the composition (by up to $70^{\circ} \mathrm{C}$ ). A simple model that accounts for the thermodynamics of this system, indicates that the stereochemical defects (chiral mismatches and helix reversals) affect much more the stability of single helices. Therefore, the heterochiral double helical structure predominates over the single helical structure (whilst the opposite holds for the homochiral structures), which explains the aforementioned higher viscosity of the racemic bis-urea solution. This rationale constitutes a new basis to tune the macroscopic properties of the increasing number of supramolecular polymers reported to exhibit competing chiral nanostructures.
\end{abstract}

\section{Introduction}

Supramolecular polymers, i.e. chain-like assemblies of selfcomplementary monomers, are a class of compounds with unique properties and applications. ${ }^{[1-4]}$ The directional but reversible noncovalent interactions responsible for their self-assembly provide a responsiveness ${ }^{[5]}$ towards a range of stimuli that has contributed to the development of innovative catalysts, ${ }^{[6]}$ optoelectronic materials,,${ }^{[7,8]}$ self-healing materials, ${ }^{[9-11]}$ chiroptical switches ${ }^{[12]}$ and gels ${ }^{[13-15]}$ amongst other applications.

It was recently realized that the properties of these supramolecular polymers can be considerably diversified when their formation occurs in competition with other assemblies. Indeed, pathway complexity can lead to supramolecular polymorphism, when two supramolecular polymers form under kinetic $^{[16-21]}$ or thermodynamic ${ }^{[22-35]}$ control. In the latter case, the transition between the two competing structures can be responsible for unusual behaviors such as self-assembly triggered by increasing the temperature ${ }^{[28]}$ or by dilution. ${ }^{[23]}$ The modification of the supramolecular structure is particularly useful when it leads to a controllable and sudden change of macroscopic (such as rheological ${ }^{[22,30]}$ or emissive ${ }^{[31,32]}$ ) properties. In addition, the sharpness of the transition can actually be exploited to

[a] Dr. V. Ayzac, Dr. M. Dirany, Dr. M. Raynal, Dr. B. Isare, Dr. L. Bouteiller

Sorbonne Université, CNRS, Institut Parisien de Chimie Moléculaire (IPCM), Equipe Chimie des Polymères, F-75005 Paris, France E-mail: laurent.bouteiller@sorbonne-universite.fr @Polymers_SU quantify weak intermolecular interactions ${ }^{[36,37]}$ or solvation effects. ${ }^{[38]}$

In this context, chirality is often used as a probe to allow monitoring subtle structural changes by circular dichroism (CD) spectroscopy. ${ }^{[16,39-43]}$ Moreover, chirality also directly impacts the thermodynamic stability of the assemblies. In the case of fibrillar self-assemblies or gels, heterochiral contacts can either increase or decrease the stability of the assemblies, compared to the homochiral situation. ${ }^{[44-49]}$ In the case of supramolecular polymers made by stacking of a single row of monomers, rare cases exist where heterochiral dimers are more stable than homodimers, ${ }^{[50,51]}$ but the usual situation is that heterochiral contacts lead to stereochemical defects. ${ }^{[52-55]}$ When a heterochiral copolymer is formed by mixing two enantiomeric monomers, mismatches and helix reversals occur that destabilize the copolymer. If interpolymer interactions are negligible, the stability of the copolymer is therefore expected to increase with the enantiomeric purity as a result of the presence of fewer chiral defects. ${ }^{[56,57]}$ Indeed, Shikata et al. have shown that an increase of the enantiomeric purity of a benzene-1,3,5-tricarboxamide monomer results in fewer defects along the supramolecular chains and thus in a higher viscosity of the solution. ${ }^{[58]}$

Now, the situation is more complex when a chiral monomer can self-assemble through two distinct pathways: both resulting supramolecular polymers can potentially be affected by packing defects, so that the net result is difficult to predict. For example, we show herein that a racemic mixture of bis-urea stereoisomers forms thermodynamically stable heterochiral assemblies that result in a more viscous solution than that of homochiral assemblies formed by its chiral non-racemic stereoisomers. We show that this counter-intuitive result can actually be traced to a huge relative stability difference of the competing assemblies (ca $70^{\circ} \mathrm{C}$ ), that can in turn be rationalized by a thermodynamic model that quantitatively accounts for the stereochemical defects.

\section{Results and Discussion}

The molecules described in this work contain four stereocenters (Fig. 1). In the following, we focus our attention only on the effect of the stereochemistry of the two valine units. The two ethylhexyl groups, that are used exclusively as racemates to improve solubility, ${ }^{[59]}$ are assumed to have a negligible influence on the self-assembling bis-urea core. rac $^{2}$-Val was synthesized by reacting an amine prepared from racemic valine with 2,4toluenediisocyanate and is therefore a mixture of four isomers (neglecting the isomerism due to the ethylhexyl groups). As previously reported ${ }^{[60]}$ it is readily soluble in non-polar solvents like toluene, where it forms a viscoelastic solution. Surprisingly, in the same conditions, SS-Val (derived from enantiopure S-valine) forms a fluid solution (Fig. 1). Small angle neutron scattering (SANS) measurements prove in both cases the formation of long and rigid rod-like assemblies ( $q^{-1}$ behavior at low wavevector $q$, Fig. 2). However, the scattered intensities differ by a factor of two at low q, indicating a difference in linear density of these one- 
dimensional supramolecular assemblies. A fit of the data with the form factor of long rigid rods with a circular cross section and a uniform scattering length density yields the values summarized in Table 1. These values indicate the presence of two (respectively one) monomers in the cross-section for $\mathrm{rac}^{2}$-Val (respectively SSVal). The thicker rods can be expected to have a slower breaking dynamics, ${ }^{[22]}$ which is qualitatively consistent with the obvious difference in viscosity of the samples (Fig. 1). SANS data show that at higher temperature $\left(70^{\circ} \mathrm{C}\right), \mathrm{rac}^{2}$-Val forms the same rods as $S S$-Val does at $20^{\circ} \mathrm{C}$ (Table 1). This actually suggests that $R R$, $S S$ (and possibly $R S$ and $S R$ ) monomers mix together and play a role in tuning the respective stability of the two rod-like structures. The influence of the optical purity of the monomers on the rheological properties of the solution is also observed in methylcyclohexane $(\mathrm{MCH})$ : mixing at room temperature the fluid solutions of $S S$-Val and $R R$-Val led to a viscous solution of racVal (see movie as supplementary material), which further demonstrates the dynamic nature of the supramolecular assemblies.
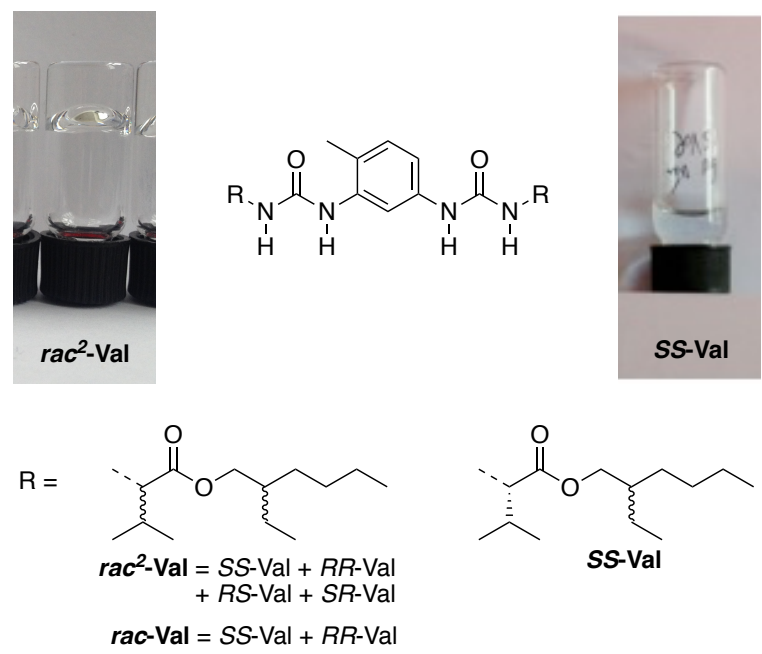

Figure 1. Structure of bis-ureas and photograph of their solutions at $10 \mathrm{mM}$ (ca $6 \mathrm{~g} / \mathrm{L}$ ) in toluene (see also video as supplementary material).

This phenomenon was characterized more quantitatively by circular dichroism (CD) in $\mathrm{MCH}$. Fig. 3a shows the $\mathrm{CD}$ spectrum of SS-Val in $\mathrm{MCH}$ at $20^{\circ} \mathrm{C}$. The presence of a strong negative band at $233 \mathrm{~nm}$ is a clear sign of supramolecular chirality because this band is absent at high temperature $\left(120^{\circ} \mathrm{C}\right)$. FTIR spectroscopy (Fig. S1) confirms that SS-Val forms hydrogen bonded assemblies in $\mathrm{MCH}$ at $20^{\circ} \mathrm{C}$ and SANS (Fig. S2, Table 1) proves that they consist in long rigid rods with a single monomer in the cross-section. Interestingly, a decrease in temperature triggers a significant change in the shape of the CD (Fig. 3a), UVVis (Fig. 3b) and FT-IR (Fig. S1a) spectra. These combined spectroscopic and scattering analyses prove that SS-Val selfassembles into helical rod-like objects, with two molecules (respectively, one molecule) in the cross-section at low (respectively, high) temperature. Their precise supramolecular structure has no consequence on the following analysis, but we surmise that SS-Val forms a double helix at low temperature and a single helix at high temperature, that are similar to the ones modelled for a structurally-related bis-urea monomer. ${ }^{[37]}$

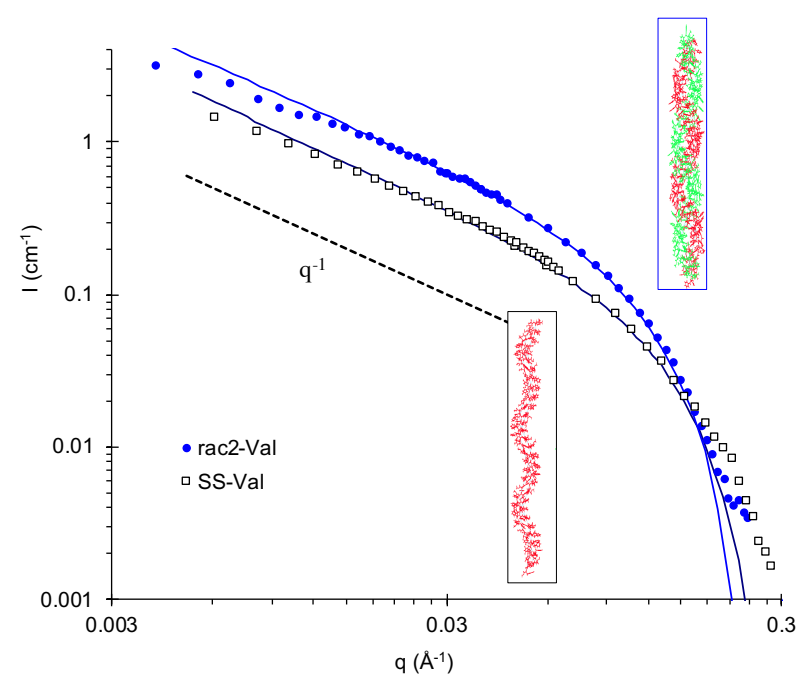

Figure 2. SANS analyses of bis-ureas $\mathrm{rac}^{2}$-Val and SS-Val performed at $20^{\circ} \mathrm{C}$ and at a concentration of ca. $6 \mathrm{~g} / \mathrm{L}(10 \mathrm{mM})$ in toluene-d8. The curves are fitted according to the form factor for infinitely long ${ }^{[61,62]}$ rigid rods with a circular cross section and a uniform scattering length density. These features are reminiscent of the double helix and single helix structures found for similar bis-ureas (recalled as insets). ${ }^{[37]}$

Table 1. Geometrical radius $(r)$, linear density $\left(n_{L}\right)$ and number of bis-urea molecules $(n)$ in the cross-section of the cylindrical objects deduced from a fit ${ }^{[61]}$ of the SANS data at a concentration of ca. $6 \mathrm{~g} / \mathrm{L}(10 \mathrm{mM})$.

\begin{tabular}{ccccccc}
\hline bis-urea & solvent & $\begin{array}{c}\mathrm{T} \\
\left({ }^{\circ} \mathrm{C}\right)\end{array}$ & $\begin{array}{c}\mathrm{T}^{\star *} \\
\left({ }^{\circ} \mathrm{C}\right)\end{array}$ & $r(\AA)$ & $n_{L}\left(\AA^{-1}\right)$ & $n^{[\mathrm{d}]}$ \\
\hline rac $^{2}$-Val ${ }^{[\mathrm{a}]}$ & $\mathrm{C}_{7} \mathrm{D}_{8}$ & 20 & $35.5^{[\mathrm{b}]}$ & 16 & 0.48 & 2.2 \\
$\mathrm{rac}^{2}$-Val ${ }^{[\mathrm{a}]}$ & $\mathrm{C}_{7} \mathrm{D}_{8}$ & 70 & $35.5^{[\mathrm{b}]}$ & 9 & 0.18 & 0.8 \\
SS-Val & $\mathrm{C}_{7} \mathrm{D}_{8}$ & 20 & $<10^{[\mathrm{b}]}$ & 12 & 0.23 & 1.1 \\
SS-Val & $\mathrm{C}_{7} \mathrm{D}_{14}$ & 20 & $-2.6^{[\mathrm{c}]}$ & 13 & 0.24 & 1.1 \\
\hline
\end{tabular}

[a] Data from [60]. [b] Measured by nDSC. [c] Measured by CD. [d] Number of bis-urea molecules in the cross-section, assuming a repeat distance of $4.6 \AA$.

The transition between the two supramolecular structures of SS$\mathrm{Val}$ is revealed by an abrupt change in the intensities of CD (Fig. 4a) and FTIR (Fig. S1b) signals in the range from ca. -10 to $0^{\circ} \mathrm{C}$. The transition temperature $\left(T^{\star *}\right)$ has thus been measured as the midpoint of the jump in $C D$ signal intensity for various mixtures of $S S-V a l$ and $R R$-Val (Fig. 4a). Since the racemic mixture is CD silent, the transition was measured by calorimetry (nDSC) (Fig. S3). ${ }^{[63]}$ Fig. $4 \mathrm{~b}$ shows that the CD, FTIR and nDSC data are consistent and that the evolution of the transition temperature is a strong function of the enantiomeric excess (ee). The racemic mixture (rac-Val) has a transition temperature that is $70^{\circ} \mathrm{C}$ higher than SS-Val and the relationship between $T^{* *}$ and the ee is highly 
nonlinear. It confirms that $S S$-Val and $R R$-Val co-assemble and form heterochiral helical structures. Mixing $R R$-Val with $S S$-Val leads to a shift of the transition to higher temperatures: it therefore means that mixing the isomers either strongly stabilizes the low temperature structure or strongly destabilizes the high temperature structure. The stability of one-dimensional assemblies of chiral monomers is well-known to be affected by the presence of stereochemical defects such as mismatches (i.e. the presence of an enantiomer in a helix with its nonpreferred helicity) and helix reversals (i.e. a change of helicity within the assembly). ${ }^{[54]}$ In the following part we propose a simple model to test if these intriguing results can be quantitatively accounted for.
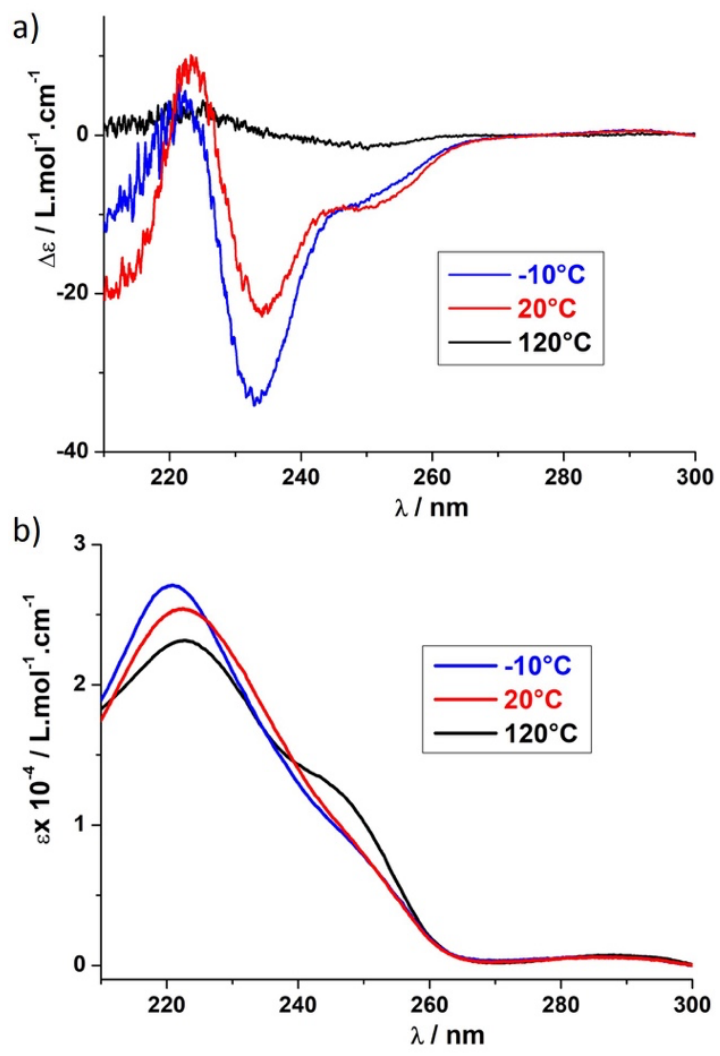

Figure 3. CD (a) and UV (b) spectra of SS-Val measured at various temperatures in $\mathrm{MCH}(1 \mathrm{mM})$

In the case of a scalemic mixture containing an arbitrary enantiomeric excess (ee) of $S S$-Val and $R R$-Val, the relative stability of the two kinds of supramolecular polymers is ruled by the free energy difference $\Delta G$ of binding a single monomer in the two types of assemblies [Eq. (1)]:

$\Delta G(e e)=G_{\text {high }}(e e)-G_{\text {low }}(e e)$

We decompose each of these free energies into two contributions: the part that is due to stereochemical defects and the part that is insensitive to them, i.e. that does not depend on ee [Eq. (2)]: $G_{\text {high }}(e e)=G_{\text {high }}^{\text {defects }}(e e)-G_{\text {high }}^{0}$
$G_{\text {high }}^{\text {defect }}(e e)=h_{\text {high }}(e e) \cdot H R P_{\text {high }}+m_{\text {high }}(e e) \cdot M M P_{\text {high }}$ (3) where $H R P_{\text {high }}$ (resp. $M M P_{\text {high }}$ ) is the penalty for a helix reversal (resp. for a mismatch) in the high temperature supramolecular polymer, and $h_{\text {high }}$ and $m_{\text {high }}$ are the associated fractions of defects.
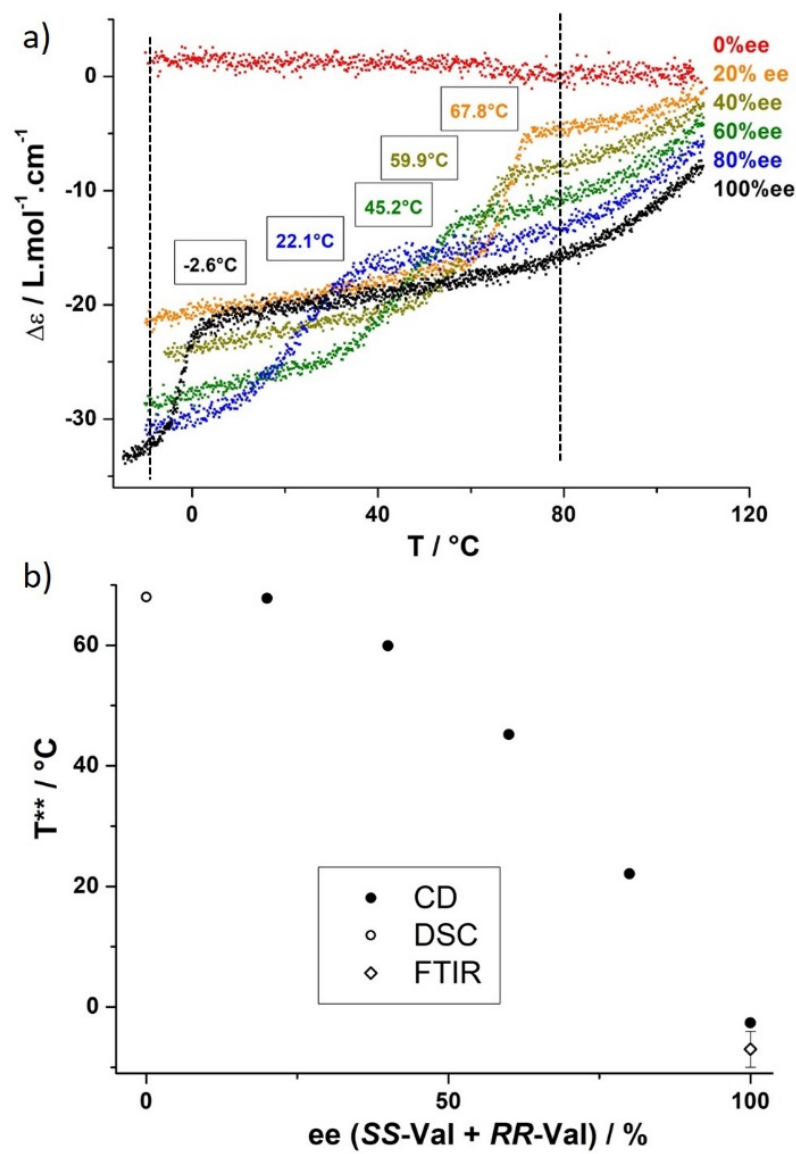

Figure 4. (a) CD intensity at $233 \mathrm{~nm}$ versus temperature for $S S-V a l / R R-V a l$ mixtures of various ee (100\% ee corresponds to SS-Val). Conditions: $1 \mathrm{mM}$ in $\mathrm{MCH}$. The dashed vertical lines materialize the temperatures selected for net helicity measurements (Fig. 5). (b) Transition temperature derived from CD (a) or from FTIR (Figure S1) or nDSC (Figure S3) measurements.

Similarly, [Eq. (4)]:

$G_{\text {low }}(e e)=G_{\text {low }}^{\text {defects }}(e e)-G_{\text {low }}^{0}$

with [Eq. (5)]:

$G_{\text {low }}^{\text {defts }}(e e)=h_{\text {low }}(e e) \cdot H R P_{\text {low }}+m_{\text {low }}(e e) \cdot M M P_{\text {low }}$

Therefore, [Eq. (6)]:

$\Delta G(e e)=\Delta G^{\text {defects }}(e e)-\Delta G^{0}$

with [Eq. (7)]:

$\Delta G^{\text {defects }}(e e)=h_{\text {high }}(e e) \cdot H R P_{\text {high }}+m_{\text {high }}(e e) \cdot M M P_{\text {high }}-$

$h_{\text {low }}(e e) \cdot H R P_{\text {low }}-m_{\text {low }}(e e) \cdot M M P_{\text {low }}$

Since the fraction of defects is directly fixed by the value of the associated penalty (through the Boltzmann distribution), we see that the influence of ee can be quantitatively described by the four energetic parameters: $H R P_{\text {high }}, M M P_{\text {high }}, H R P_{\text {low }}$ and $M M P_{\text {low }}$. 
We then consider the free energy difference between the scalemic and the enantiopure systems [Eq. (8)]:

$\Delta \Delta G(e e)=\Delta G(e e)-\Delta G(0)=\left[h_{\text {high }}(e e)-h_{\text {high }}(0)\right] \cdot H R P_{\text {high }}+$ $\left[m_{\text {high }}(e e)-m_{\text {high }}(0)\right] \cdot M M P_{\text {high }}-\left[h_{\text {low }}(e e)-h_{\text {low }}(0)\right] \cdot$

$H R P_{\text {low }}-\left[m_{\text {low }}(e e)-m_{\text {low }}(0)\right] \cdot M M P_{\text {low }}$

This free energy difference is directly related to the experimentally determined transition temperatures and can be calculated according to the supramolecular balance principle [Eq. (9)]:[36][37]

$\Delta \Delta G(e e)=\Delta H^{\text {scalemic }}\left(T^{* * \text { scalemic }}-T^{* * S S}\right) /_{T^{* * S S}}$

where both transition temperatures and the enthalpy have been measured (Fig. $4 \mathrm{~b}$ and S3). Therefore, the energetic penalties are constrained by equation (10):

$\left[h_{\text {high }}(e e)-h_{\text {high }}(0)\right] \cdot H R P_{\text {high }}+\left[m_{\text {high }}(e e)-m_{\text {high }}(0)\right] \cdot$

$M M P_{\text {high }}-\left[h_{\text {low }}(e e)-h_{\text {low }}(0)\right] \cdot H R P_{\text {low }}-\left[m_{\text {low }}(e e)-\right.$

$\left.m_{\text {low }}(0)\right] \cdot M M P_{\text {low }}=\Delta H^{\text {scalemic }}\left(T^{* * \text { scalemic }}-T^{* * S S}\right) / T_{T^{* * S S}}($

Moreover, following the van Gestel model for majority-rules experiments, ${ }^{[64]}$ the helix reversal and mismatch penalties can be determined from the variation of the net helicity as a function of ee. Therefore, we selected temperatures below and above the lowest and highest $T^{* *}$ values, respectively, to ensure that a single supramolecular polymer is present and we measured the $C D$ spectra of the scalemic supramolecular polymers, both for the single helix supramolecular polymer $\left(\right.$ at $80^{\circ} \mathrm{C}$ ) and the double helix supramolecular polymer (at $-10^{\circ} \mathrm{C}$ ) (Fig. S4). The deduced net helicity at $233 \mathrm{~nm}$ is plotted in Fig. 5a (single helix) and Fig. $5 \mathrm{~b}$ (double helix) as a function of the ee of the SS-Val / RR-Val mixture. These plots show that the extent of net helicity amplification is strong for double helices, for which the net helicity reaches $70 \%$ for mixtures only slightly biased from the racemic mixture $(20 \%$ ee), while it is modest for single helices, for which net helicity varies nearly linearly versus ee.

Fig. $5 \mathrm{c}$ shows the thermodynamic data of Fig. $4 \mathrm{~b}$ that is replotted according to equation (9). Finally, we used the equations of the van Gestel model (applied both to the single and double helices) together with equation (10) to simultaneously fit the data. The best fit is represented on Figs. $5 \mathrm{a}$ to $5 \mathrm{c}$ and the values obtained for the energetic penalties are collected in Table 2. The extent of net helicity amplification is reflected in the values of the energetic parameters deduced from the fit: the double helix is characterized by both a higher HRP and a lower MMP than the single helix. Both features are known to be necessary for amplification. ${ }^{[64,66]}$ In addition, the larger HRP value for the double helix is expected, since a helix reversal should be more unfavorable in a thicker, probably less flexible, supramolecular polymer.

Table 2. Energetic parameters for stereochemical defects in SS-Val / RR-Val mixtures, extracted from the fits (Fig. 5).

\begin{tabular}{ccc}
\hline $\begin{array}{c}\text { temperature } \\
\left({ }^{\circ} \mathrm{C}\right)\end{array}$ & $\begin{array}{c}\text { helix reversal penalty } \\
(\mathrm{kJ} / \mathrm{mol})\end{array}$ & $\begin{array}{c}\text { mismatch penalty } \\
(\mathrm{kJ} / \mathrm{mol})\end{array}$ \\
\hline 80 & $H R P_{\text {high }}=4.8$ & $M M P_{\text {high }}=1.3$ \\
-10 & $H R P_{\text {low }}=10.4$ & $M M P_{\text {low }}=0.4$ \\
\hline
\end{tabular}
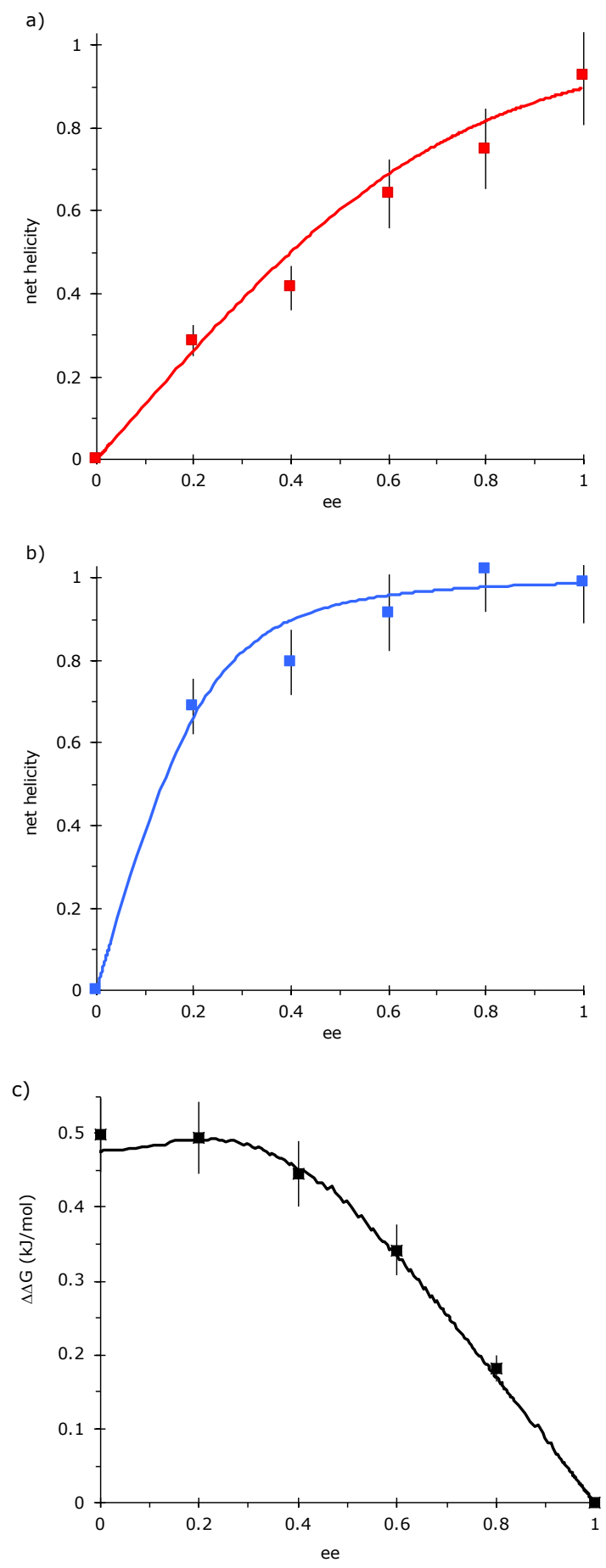

Figure 5. Majority rules experiments for $S S$-Val / $R R$-Val mixtures. (a) Net helicity of the high temperature supramolecular polymer (measured at $80^{\circ} \mathrm{C}$ ). (b) Net helicity of the low temperature supramolecular polymer (measured at $10^{\circ} \mathrm{C}$ ). Conditions: $1 \mathrm{mM}$ in $\mathrm{MCH}, \lambda=233 \mathrm{~nm}$. The $\mathrm{CD}$ spectra are shown in Fig. S4. (c) Relative stability of two supramolecular polymers. Continuous lines represent the fits with the parameters shown in Table 2. 
With these energetic parameters in hand, it is now possible to address the initially unanswered question whether the higher transition temperature of the racemic mixture is due to the stabilization of the low temperature supramolecular polymer or to the destabilization of the high temperature supramolecular polymer. Fig. $6 a$ and $6 \mathrm{c}$ show the fraction of defects that are present at temperatures above or below the transition temperature and Fig. $6 \mathrm{~b}$ and $6 \mathrm{~d}$ show the associated energetic penalties derived from equations (3) and (5). For each supramolecular polymer, mismatches are much more numerous than helix reversals (i.e. $m_{\text {high }}>h_{\text {high }}$ and $m_{\text {low }}>h_{\text {low }}$ ), but their energetic weight are similar (Fig. $6 \mathrm{~b}$ and $6 \mathrm{~d}$ ) because of the much higher penalty for a helix reversal than for a mismatch (i.e. $H R P_{h i g h}$ $>M M P_{\text {high }}$ and $H R P_{\text {low }}>M M P_{\text {low }}$ ). As expected, for both supramolecular polymers the racemic composition contains more stereochemical defects that the non-racemic one, however the high temperature supramolecular polymer is much more destabilized by this effect than the low temperature one, because the difference between $G_{\text {high }}^{\text {defects }}$ (Fig. 6b) and $G_{\text {low }}^{\text {defects }}$ (Fig. 6d) is more than twice larger for the heterochiral than for the homochiral supramolecular polymer). This implies that for heterochiral assemblies, the double helical structure predominates over the single helical one, while the opposite holds for homochiral assemblies. Subtle energetic differences governing the stability of the two competing helical structures thus translate into a major change of the macroscopic properties of solutions of racemic versus enantiopure monomers.
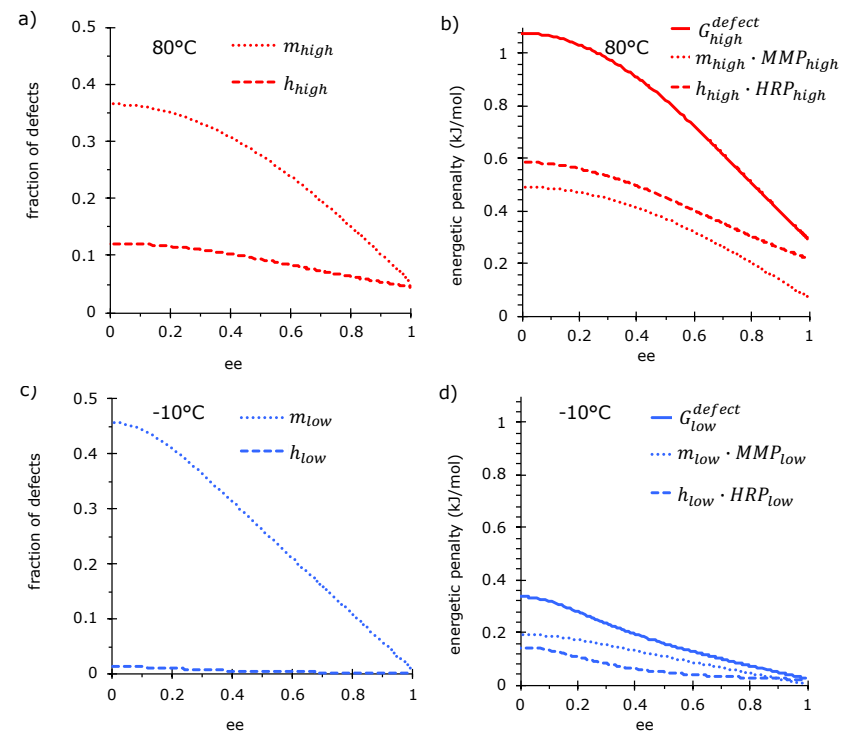

Figure 6. Fraction of defects (at $80^{\circ} \mathrm{C}$ (a) and at $-10^{\circ} \mathrm{C}$ (c)) and their energetic contribution (at $80^{\circ} \mathrm{C}(\mathrm{b})$ and at $-10^{\circ} \mathrm{C}(\mathrm{d})$ ) (calculated according to equations (3) and (5)), as a function of the enantiomeric excess of $S S$-Val / RR-Val mixtures.

\section{Conclusions}

Stereochemical defects are expected to destabilize a supramolecular polymer formed by a racemic mixture of monomers, compared to the enantiopure supramolecular polymer. However, when the monomers can assemble into two competing supramolecular polymers, the situation can be more complex. SS-Val self-assembles into two distinct supramolecular polymers; and the supramolecular polymer that is stable at low temperature is more viscous than the one stable at high temperature. When $R R$-Val is introduced in the system, it creates stereochemical defects that destabilize both supramolecular polymers. However, it is not possible, a priori, to predict how the relative stability of the two supramolecular polymers should evolve. The general thermodynamic model that we propose allows to rationalize this behavior based on four energetic penalties (for chiral mismatches and for helix reversals associated to both polymers). In the present experimental system, the high temperature supramolecular polymer is much more affected by stereochemical defects than the low temperature one, so that the relative stability of the low temperature supramolecular polymer is increased: its range of stability is increased by ca. $70^{\circ} \mathrm{C}$. Consequently, at room temperature, the high temperature (low viscosity) supramolecular polymer is dominant in the case of SS-Val, but the low temperature (high viscosity) supramolecular polymer wins over in the case of the racemic mixture of monomers. This rationale should help understand the influence of chirality on the macroscopic properties of the increasing number of competing supramolecular chiral nanostructures reported in the literature.

\section{Acknowledgements}

This work was supported by the French Agence Nationale de la Recherche (project ANR-12-BS08-0019 BalanceSupra). Raphaëlle Pique, Jacques Jestin (LLB, Saclay) and Nicolas Vanthuyne (iSm2, Marseille) are acknowledged for assistance with the synthesis, SANS experiments, and chiral HPLC analyses, respectively.

Keywords: bis-urea $\cdot$ helix reversal $\cdot$ net helicity amplification • pathway complexity $\bullet$ supramolecular polymer

[1] L. Brunsveld, B. J. B. Folmer, E. W. Meijer, R. P. Sijbesma, Chem. Rev. 2001, 101, 4071-4097.

[2] T. F. A. De Greef, M. M. J. Smulders, M. Wolffs, A. P. H. J. Schenning, R. P. Sijbesma, E. W. Meijer, Chem. Rev. 2009, 109, 5687-5754.

[3] L. Yang, X. Tan, Z. Wang, X. Zhang, Chem. Rev. 2015, 115, 7196-7239.

[4] B. Isare, S. Pensec, M. Raynal, L. Bouteiller, C. R. Chim. 2016, 19, 148-156.

[5] X. Yan, F. Wang, B. Zheng, F. Huang, Chem. Soc. Rev. 2012, 41, 6042-6065.

[6] Y. Li, L. Bouteiller, M. Raynal, ChemCatChem 2019, 11, 5212-5226.

[7] F. J. M. Hoeben, P. Jonkheijm, E. W. Meijer, A. P. H. J. Schenning, Chem. Rev. 2005, 105, 1491-1546.

[8] S. S. Babu, V. K. Praveen, A. Ajayaghosh, Chem. Rev. 
2014, 114, 1973-2129.

[9] L. R. Hart, J. L. Harries, B. W. Greenland, H. M. Colquhoun, W. Hayes, Polym. Chem. 2013, 4, 4860-4870.

[10] F. Herbst, D. Döhler, P. Michael, W. H. Binder, Macromol. Rapid Commun. 2013, 34, 203-220.

[11] L. Simonin, G. Falco, S. Pensec, F. Dalmas, J.-M. Chenal, F. Ganachaud, A. Marcellan, L. Chazeau, L. Bouteiller, Macromolecules 2021, 54, 888-895.

[12] J. J. D. de Jong, L. N. Lucas, R. M. Kellogg, J. H. van Esch, B. L. Feringa, Science 2004, 304, 278-281.

[13] A. R. Hirst, B. Escuder, J. F. Miravet, D. K. Smith, Angew. Chem., Int. Ed. 2008, 47, 8002-8018; Angew. Chem. 2008, 120, 8122-8139.

[14] A. Dawn, T. Shiraki, S.-I. Haraguchi, S.-I. Tamaru, Seiji. Shinkai, Chem. Asian J. 2011, 6, 266-282.

[15] B. Isare, L. Petit, E. Bugnet, R. Vincent, L. Lapalu, P. Sautet, L. Bouteiller, Langmuir 2009, 25, 8400-8403.

[16] P. A. Korevaar, S. J. George, A. J. Markvoort, M. M. J. Smulders, P. A. J. Hilbers, A. P. H. J. Schenning, T. F. A. De Greef, E. W. Meijer, Nature 2012, 481, 492-496.

[17] A. Langenstroer, K. K. Kartha, Y. Dorca, J. Droste, V. Stepanenko, R. Q. Albuquerque, M. R. Hansen, L. Sanchez, G. Fernandez, J. Am. Chem. Soc. 2019, 141, 5192-5200.

[18] M. Wehner, M. I. S. Röhr, M. Bühler, V. Stepanenko, W. Wagner, F. Würthner, J. Am. Chem. Soc. 2019, 141, 60926107.

[19] E. E. Greciano, J. Calbo, E. Ortí, L. Sánchez, Angew. Chem. Int. Ed. 2020, 59, 17517-17524; Angew. Chem. 2020, 132, 17670-17677.

[20] M. Wehner, F. Würthner, Nat. Rev. Chem. 2020, 4, 38-53.

[21] T. Fukui, S. Kawai, S. Fujinuma, Y. Matsushita, T. Yasuda, T. Sakurai, S. Seki, M. Takeuchi, K. Sugiyasu, Nat. Chem. 2017, 9, 493-499.

[22] L. Bouteiller, O. Colombani, F. Lortie, P. Terech, J. Am. Chem. Soc. 2005, 127, 8893-8898.

[23] F. Helmich, C. C. Lee, M. M. L. Nieuwenhuizen, J. C. Gielen, P. C. M. Christianen, A. Larsen, G. Fytas, P. E. L. G. Leclère, A. P. H. J. Schenning, E. W. Meijer, Angew. Chem., Int. Ed. 2010, 49, 3939-3942; Angew. Chem. 2010, 122, 40314034.

[24] J. Baram, H. Weissman, Y. Tidhar, I. Pinkas, B. Rybtchinski, Angew. Chem., Int. Ed. 2014, 53, 4123-4126; Angew. Chem. 2014, 126, 4207-4210.

[25] D. van der Zwaag, P. A. Pieters, P. A. Korevaar, A. J. Markvoort, A. J. H. Spiering, T. F. A. de Greef, E. W. Meijer, J. Am. Chem. Soc. 2015, 137, 12677-12688.

[26] M. Yamauchi, T. Ohba, T. Karatsu, S. Yagai, Nat. Commun. 2015, 6, 8936.

[27] M. Hifsudheen, R. K. Mishra, B. Vedhanarayanan, V. K. Praveen, A. Ajayaghosh, Angew. Chem. Int. Ed. 2017, 56, 12634-12638; Angew. Chem. 2017, 129, 12808-12812. [28] K. Venkata Rao, D. Miyajima, A. Nihonyanagi, T. Aida, Nat. Chem. 2017, 9, 1133-1139.

[29] M. F. J. Mabesoone, A. J. Markvoort, M. Banno, T. Yamaguchi, F. Helmich, Y. Naito, E. Yashima, A. R. A. Palmans, E. W. Meijer, J. Am. Chem. Soc. 2018, 140, 7810-7819.

[30] V. Ayzac, Q. Sallembien, M. Raynal, B. Isare, J. Jestin, L. Bouteiller, Angew. Chem. Int. Ed. 2019, 58, 13849-13853; Angew. Chem. 2019, 131, 13987-13991.

[31] H. Jiang, Y. Jiang, J. Han, L. Zhang, M. Liu, Angew. Chem. Int. Ed. 2019, 58, 785-790; Angew. Chem. 2019, 131, 822-827.

[32] F. Li, X. Li, Y. Wang, X. Zhang, Angew. Chem. Int. Ed. 2019, 58, 17994-18002; Angew. Chem. 2019, 131, 1814418152.

[33] N. J. Van Zee, B. Adelizzi, M. F. J. Mabesoone, X. Meng,
A. Aloi, R. H. Zha, M. Lutz, I. A. W. Filot, A. R. A. Palmans, E. W. Meijer, Nature 2018, 558, 100-103.

[34] K. V. Rao, M. F. J. Mabesoone, D. Miyajima, A.

Nihonyanagi, E. W. Meijer, T. Aida, J. Am. Chem. Soc. 2020, 142, 598-605.

[35] N. J. Van Zee, M. F. J. Mabesoone, B. Adelizzi, A. R. A. Palmans, E. W. Meijer, J. Am. Chem. Soc. 2020, 142, 2019120200.

[36] M. Roman, C. Cannizzo, T. Pinault, B. Isare, B. Andrioletti, P. van der Schoot, L. Bouteiller, J. Am. Chem. Soc. 2010, 132, 16818-16824.

[37] V. Ayzac, M. Raynal, B. Isare, J. Idé, P. Brocorens, R.

Lazzaroni, T. Etienne, A. Monari, X. Assfeld, L. Bouteiller, Phys. Chem. Chem. Phys. 2017, 19, 32443-32450.

[38] L. Bouteiller, P. van der Schoot, J. Am. Chem. Soc. 2012, 134, 1363-1366.

[39] A. Lohr, M. Lysetska, F. Würthner, Angew. Chem., Int. Ed. 2005, 44, 5071-5074; Angew. Chem. 2005, 117, 5199-5202.

[40] P. Jonkheijm, P. van der Schoot, A. P. H. J. Schenning, E. W. Meijer, Science 2006, 313, 80-83.

[41] A. Lohr, F. Würthner, Angew. Chem., Int. Ed. 2008, 47 1232-1236; Angew. Chem. 2008, 120, 1252-1256.

[42] S. Ghosh, X.-Q. Li, V. Stepanenko, F. Würthner, Chem.

Eur. J. 2008, 14, 11343-11357.

[43] Y. Dorca, E. E. Greciano, J. S. Valera, R. Gómez, L. Sánchez, Chem. Eur. J. 2019, 25, 5848-5864.

[44] J. Makarevic, M. Jokic, Z. Raza, Z. Stefanic, B. KojicProdic, Mladen. Zinic, Chem. Eur. J. 2003, 9, 5567-5580. [45] T. Naota, H. Koori, J. Am. Chem. Soc. 2005, 127, 93249325.

[46] X. Zhu, Y. Li, P. Duan, M. Liu, Chem. Eur. J. 2010, 16, 8034-8040.

[47] K. J. Nagy, M. C. Giano, A. Jin, D. J. Pochan, J. P Schneider, J. Am. Chem. Soc. 2011, 133, 14975-14977. [48] Z. Shen, T. Wang, M. Liu, Langmuir 2014, 30, 1077210778.

[49] C. Kulkarni, J. A. Berrocal, M. Lutz, A. R. A. Palmans, E. W. Meijer, J. Am. Chem. Soc. 2019, 141, 6302-6309.

[50] J. Kumar, H. Tsumatori, J. Yuasa, T. Kawai, T. Nakashima, Angew. Chem. Int. Ed. 2015, 54, 5943-5947; Angew. Chem. 2015, 127, 6041-6045.

[51] M. J. Mayoral, J. Guilleme, J. Calbo, J. Aragó, F. Aparicio, E. Ortí, T. Torres, D. González-Rodríguez, J. Am. Chem. Soc. 2020, 142, 21017-21031.

[52] J. van Gestel, P. van der Schoot, M. A. J. Michels, Macromolecules 2003, 36, 6668-6673.

[53] J. van Gestel, A. R. A. Palmans, B. Titulaer, J. A. J. M. Vekemans, E. W. Meijer, J. Am. Chem. Soc. 2005, 127, 54905494.

[54] A. R. A. Palmans, E. W. Meijer, Angew. Chem., Int. Ed. 2007, 46, 8948-8968; Angew. Chem. 2007, 119, 9106-9126. [55] E. E. Greciano, J. Calbo, J. Buendía, J. Cerdá, J. Aragó, E. Ortí, L. Sánchez, J. Am. Chem. Soc. 2019, 141, 7463-7472. [56] If strong enough, this energetic bias can actually lead to self-sorted homochiral polymers. See for example the next reference.

[57] Y. Ishida, T. Aida, J. Am. Chem. Soc. 2002, 124, 1401714019.

[58] D. Ogata, T. Shikata, K. Hanabusa, J. Phys. Chem. B 2004, 108, 15503-15510.

[59] V. Simic, L. Bouteiller, M. Jalabert, J. Am. Chem. Soc. 2003, 125, 13148-13154.

[60] M. Dirany, V. Ayzac, B. Isare, M. Raynal, L. Bouteiller, Langmuir 2015, 31, 11443-11451.

[61] F. Lortie, S. Boileau, L. Bouteiller, C. Chassenieux, B. Deme, G. Ducouret, M. Jalabert, F. Laupretre, P. Terech, 
Langmuir 2002, 18, 7218-7222.

[62] The deviation from a $\mathrm{q}^{-1}$ behaviour at low $\mathrm{q}$ is probably due to repulsive interactions between rods and precludes

determination of their length.

[63] The temperature resolution of our FTIR data is too low to

measure the transition.

[64] J. van Gestel, Macromolecules 2004, 37, 3894-3898.

[65] B. Jouvelet, B. Isare, L. Bouteiller, P. van der Schoot,
Langmuir 2014, 30, 4570-4575.

[66] Y. Li, A. Hammoud, L. Bouteiller, M. Raynal, J. Am. Chem. Soc. 2020, 142, 5676-5688. 
Entry for the Table of Contents (Please choose one layout)

Layout 1:

\section{FULL PAPER}

Accounting for defects: Subtle energetic differences (chiral mismatches and helix reversals) govern the stability of two competing helical structures and translate into a major change of the macroscopic properties of solutions of racemic versus enantiopure monomers.

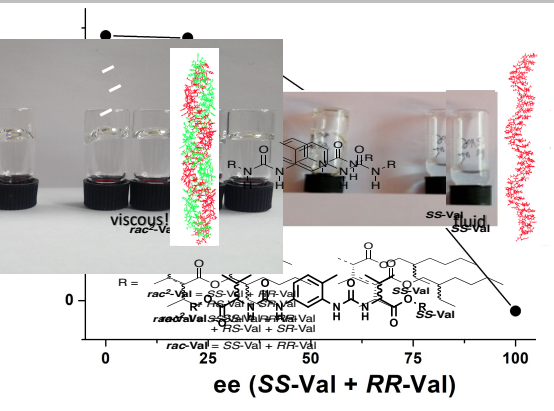

Virgile Ayzac, Mohammed Dirany, Matthieu Raynal, Benjamin Isare, Laurent Bouteiller*

Page No. - Page No.

Energetics of competing chiral supramolecular polymers 